\title{
El derecho a la salud de venezolanos en situación migratoria irregular en la jurisprudencia constitucional colombiana (2016-2019) ${ }^{1}$
}

\author{
The right to health of Venezuelans in an irregular \\ migratory situation in the Colombian constitutional \\ jurisprudence (2016-2019)
}
Gabriel Andrés Arévalo Robles ${ }^{2}$
Universidad Católica de Colombia gaarevalo@ucatolica.edu.co

Omaira Esperanza Castellanos Cortés ${ }^{3}$ Fundación Universitaria Juan de Castellanos

oecastellanos@jdc.edu.co

\footnotetext{
1 La investigación pertenece a la línea de investigación Fundamentación e Implementación de los Derechos Humanos, del grupo de investigación "Persona, Instituciones y Exigencias de Justicia", reconocido y categorizado como Tipo A1 por MINCIENCIAS y registrado con el código COL 0120899, vinculado al Centro de Investigaciones Socio jurídicas (CISJUC), adscrito y financiado por la Facultad de Derecho de la Universidad Católica de Colombia.

2 Doctor en Estudios Internacionales (Universidad del País Vasco/Euskal Herriko Unibertsitatea, UPV/EHU). Master en Estudios Internacionales. (UPV/EHU). Abogado (Universidad Libre), Sociólogo (Universidad Nacional de Colombia). Docente Investigador, Facultad de Derecho, Universidad Católica de Colombia, Grupo de Investigación Personas, instituciones y exigencias de justicia Categoría Colciencias: A1.

3 Magíster en Derechos Fundamentales y Poderes Públicos, Magíster en Globalización y Desarrollo (Universidad del País Vasco/Euskal Herriko Unibertsitatea, UPV/EHU). Abogada (Universidad de Caldas). Docente investigadora, Facultad de Ciencias Jurídicas y Políticas Internacionales, Fundación Universitaria Juan de Castellanos.
} 
Resumen: El presente artículo pretende analizar los procesos de inclusión/exclusión al derecho fundamental de la salud de ciudadanos venezolanos en situación migratoria irregular. El argumento central es que la Constitución Política de Colombia (1991) estableció una regla de excepción que da la oportunidad de suspender los derechos fundamentales a ciertos extranjeros. Cuando en sus decisiones, la Corte Constitucional adopta dicha regla, el derecho a la salud de personas con status migratorio irregular queda limitado y la gran mayoría de veces excluidas de sus derechos constitucionales. Para desarrollar esta afirmación será tomada como guía la siguiente pregunta: ¿se garantizaron plenamente los derechos fundamentales a la salud, la integridad y la vida digna a los extranjeros en situación migratoria irregular en Colombia? Para responderla será usado el método de estudio conocido como línea jurisprudencial aplicado a las sentencias de la Corte Constitucional de Colombia producidas entre los años 2016 y 2019.

Palabras claves: Migración irregular, derecho a la salud, venezolanos, jurisprudencia, Colombia.

Abstrac: This article aims to analyze the processes of inclusion / exclusion of the fundamental health right of Venezuelan citizens in an irregular migratory situation. The central argument is that the Political Constitution of Colombia (1991) established an exception rule that gives the opportunity to suspend the fundamental rights of certain foreigners. When the Constitutional Court adopts this rule in his decisions, the right to health of people with irregular immigration status is limited and the vast majority of times excluded from their constitutional rights. In order to develop this affirmation, the following question will be taken as a guide: were the fundamental rights to health, integrity and a dignified life fully guaranteed to foreigners in an irregular migratory situation in Colombia? To answer it, the study method known as the jurisprudential line applied to the judgments of the Constitutional Court of Colombia produced between 2016 and 2019 will be used.

Keywords: Irregular migration, right to health, Venezuelans, jurisprudence, Colombia. 


\section{Introducción}

En cierto Foro un delegado de Derechos Humanos de la Personería de un Municipio de Colombia tomó la palabra para rebatir una sonada reclamación de los panelistas sobre la desprotección del Estado de los derechos fundamentales a los migrantes y solicitantes de asilo venezolanos. El funcionario alegó que ya les habían ayudado 'en lo que se podía' y, por tanto, 'no debería culparse a las instituciones de sus necesidades vitales porque los migrantes no solamente han venido por su decisión, sino que les han quitado el trabajo a los locales, usado los servicios de salud y por desgracia, también han cometido ilícitos'. El panel quedó en silencio y un poco perplejo. Las personerías en cada ciudad velan por la promoción y protección de los derechos humanos, sin embargo, tampoco parecía existir un rotundo desacuerdo en el público y tampoco, parece que su posición estuviera fuera de la práctica de las instituciones del Estado Social del Derecho colombiano.

La intensa movilidad transfronteriza de ciudadanos venezolanos desde el año 2015 se consolidó como una 'crisis de migración forzada' caracterizada por "vacíos de protección para el goce efectivo de los derechos humanos" ${ }^{4}$. Alrededor de 1.800 .000 migrantes venezolanos han llegado a Colombia y más de la mitad se encuentran en 'situación irregular'5. La difícil situación a la que se ven enfrentados no se ve aliviada por la actividad de los órganos del Estado encargados de salvaguardar sus derechos fundamentales. Por el contrario, las barreras administrativas por acción y/o omisión del Estado y las decisiones judiciales profundizan o transforman su tragedia según su inclinación.

Muchas personas enferman o viajan con la esperanza de tratar enfermedades que no pueden enfrentar en su país de origen. Migran niños, niñas y ancianos, discapacitados, mujeres, algunas gestantes o personas con enfermedades catastróficas. Frente a su tragedia las Entidades de Salud no les atienden argumentando su condición irregular, por su

4 Corte IDH. Resolución 2/18 2018, p. 2.

5 Migración Colombia, 2019. 
incapacidad de pago o por ambas. Muchas veces los hospitales les retienen a ellos o a sus hijos o hijas como prenda de pago. Algunos, los que cuentan con alguna suerte, son orientados por colectivos de abogados o clínicas jurídicas universitarias ${ }^{6}$ que presentan acciones legales de protección que ciertas veces son negadas o limitadas por las decisiones judiciales. De sus múltiples derechos vulnerados, la salud y la vida digna, resultan determinantes cuando se trata de la existencia real y no solo retórica, de personas y familias que desean vivir dignamente.

Lamentablemente las decisiones judiciales de la Corte Constitucional de Colombia han mostrado una clara inclinación a limitar los derechos fundamentales de los migrantes en situación de irregularidad, estableciendo un 'estado de excepción' o 'suspensión del derecho a la salud, la vida y la integridad de las personas'. Al parecer, los cálculos políticos y fiscales han animado las decisiones de la Corte, pero -al parecer- vienen siendo disimulados por argumentos de orden administrativo y legales que resultan ambiguos y hasta extraños frente a la situación humanitaria de la movilidad venezolana. Importantes dictámenes judiciales ponen en riesgo la vida a través del abandono y la desprotección legal de los migrantes en situación de irregularidad que a su vez sirven de guía para los jueces de tutela de todo el país. Las decisiones de las sentencias constitucionales han terminado por limitar el derecho a la salud y a la vida digna a casos urgentes o catastróficos.

En consecuencia, el presente artículo tiene el propósito de analizar las decisiones de la Corte Constitucional de Colombia sobre casos especiales que buscan el amparo constitucional del derecho a la salud y la vida digna de personas migrantes en situación irregular entre el año 2016 y 2019. Pretende resolver las siguientes preguntas de investigación: ¿Se garantizó plenamente los derechos fundamentales a la salud, la integridad y la vida digna a los extranjeros en situación migratoria irregular en

6 Una de las redes más importantes de impacto y cobertura nacional especializada es el Programa de Asistencia Legal a Población con Necesidad de Protección Internacional y Víctimas del Conflicto Armado conformada por alrededor de 22 Consultorios Jurídicos de diferentes Universidades. Coordinada por la Corporación Opción Legal con apoyo el apoyo de la ACNUR. 
Colombia? ¿Cuáles son los principales argumentos jurídicos esgrimidos en la jurisprudencia colombiana? y ¿Cuáles son las principales valoraciones críticas de sus decisiones? Para lograr este propósito, primero valorará teóricamente la tarea de los jueces. Segundo, expondrá críticamente las posturas de las 12 sentencias encontradas entre el año 2016 y 2019 usando el método de formulación de línea jurisprudencial.

\section{El derecho de los jueces: voluntad y argumentación}

¿Cómo justifican los jueces sus decisiones? ¿Los jueces crean un nuevo derecho con sus sentencias? o resultan ¿meros agentes de reproducción de la norma aplicada a un caso concreto? ¿pueden los jueces ser objetivos y neutrales? o ¿son actores sujetos a su ideología, religión o posición económica? Las respuestas constituyen los principales debates del siglo $\mathrm{XX}$ sin que la polémica fuera saldada a favor de alguna posición. Por el contrario, cada vez más, las opciones se fueron abriendo hasta producir un conjunto de perspectivas que van desde la rígida visión formal e instrumental de la actividad neutral del juez hasta la que considera que los jueces son creadores de normas y hasta aplicadores de política pública.

En su clásico texto sobre The force of law, Pierre Bourdieu ${ }^{7}$ explica que el derecho es un campo de batalla, determinado por relaciones de fuerza que le confieren estructura, orientan las luchas y limitan el espacio de lo posible. Para el sociólogo francés, la lucha está motivada por establecer una versión hegemónica del discurso jurídico a través de agentes investidos de competencia técnica y social reconocida para interpretar los textos jurídicos. Dichos actores buscan apropiarse de la fuerza simbólica, imponer las representaciones de la realidad por medio del lenguaje del derecho y consagrar la visión legítima del mundo social.

En el campo jurídico la interpretación está a cargo de jurisconsultos, docentes o doctrinantes que aportan una orientación teórica y, sobre todo por los jueces, magistrados y abogados que aportan una interpretación

7 BOURDIEU, (1987). 
práctica. Los jueces tiene un papel predominante porque son los encargados de saldar el conflicto. Bourdieu, sin embargo, más interesado en realizar una descripción sociológica del derecho dedica poco espacio a explicar la tarea de los jueces. Lo que resulta claro, sin embargo, es que la actividad del juez es vital dentro de la lucha y tiene un impacto sobre la vida práctica de personas y comunidades.

La tarea de los jueces no es unívoca. La antigua posición formalista consideraba que los jueces por medio de silogismos aplicaban reglas a los hechos y llegaban a conclusiones lógicas y verdaderas. Esto era posible porque los conceptos jurídicos al ser inmutables y eternos acarreaban soluciones jurídicas lógicas. El realismo jurídico norteamericano denunció esta visión, señaló que los jueces tomaban decisiones motivados por opiniones políticas, posturas morales o incluso, emocionales y luego las justifican con razones jurídicas y antecedentes judiciales ajustando sus principales consideraciones ${ }^{8}$. Los realistas son escépticos sobre las reglas que se aplican a los juicios debido a la indeterminación de las normas jurídicas y porque hay razones no-jurídicas que motivan las decisiones de los jueces. Consideran que las normas al ser generales tienen un carácter ambiguo e incierto, de manera que la interpretación judicial escapa a la seguridad jurídica promulgada por el formalismo jurídico.

La indeterminación del derecho consiste en la ausencia de certeza sobre el significado de cada una de las normas. La tarea del juez no es sencilla pues resulta difícil identificar las normas que deben ser aplicables a cada uno de los casos y adecuar sus abstractas categorías a las proposiciones fácticas. Por tanto, el juez está avocado a maniobrar sus razonamientos y usar técnicas de interpretación que muchas veces son contradictorias. Además, la interpretación de la ley adquiere un papel predominante sobre sus contenidos, significados y alcances. Poco importa si se trata del supuesto de casos fáciles o difíciles, en el fondo siempre la decisión interpretativa es discrecional. Jueces y doctrinantes han reconocido que la producción de sentencias es producto de una do-

8 Hutcheson, (1929); Green, (2005). 
ble actividad legislativa y política ${ }^{9}$.

Herederos de la crítica del realismo, la corriente de los Critical Legal Studies, retoma la discusión sobre el razonamiento jurídico de la decisión judicial. Duncan Kennedy ${ }^{10}$ critica la retórica jurídica que aparenta ser neutral e imparcial pero oculta factores determinantes como la ideología. Aunque no desconoce el papel de la argumentación jurídica, considera que la decisión judicial es una labor ideológica y política posible por la indeterminación del derecho positivo que es un sistema de normas lleno de tensiones y contradicciones, vacíos y no pocas incoherencias internas. Kennedy afirma que la defensa del ordenamiento jurídico y la función judicial apolítica forma parte de una cultura dominante que favorece a grupos hegemónicos de la sociedad. Significa que si la actividad judicial tiene un componente ideológico, los jueces se pueden inclinar por su tendencia hacia diferentes clases sociales.

Hasta acá es viable afirmar que el derecho es un campo de batalla donde diferentes actores disputan el significado de las normas a través de la interpretación. Lo hacen dentro de unas lógicas y gramáticas autorizadas, como si se tratara de la gestión de un conflicto reglado. Sin embargo, los jueces tienen el papel predominante porque a diferencia de los abogados o los doctrinantes, tienen el poder de decidir, mientras los demás cuentan con la posibilidad apenas de la influencia. Las decisiones no son imparciales y están impregnadas de voluntad e influenciadas por la ideológica y cultura de los jueces. Pese a estar de acuerdo con dicha afirmación, no se puede afirmar su absoluta discrecionalidad porque no pueden escapar a la argumentación jurídica y al ofrecimiento de razones que justifican su decisión la cual tiene implicaciones más que individuales.

Autores como MacCormick consideran que la motivación de las decisiones ofrecen una limitación a la discresionalidad del juez ${ }^{11}$ o la irracionalidad que le acusan los realistas. Este enfoque intenta solventar la "desprestigiada" acción volitiva del juez pero sin entrar a justificar el

9 ThOMAs, (2005)

10 KENNEDY, (2009)

11 MACCORMICK Y WEINBERGER, (1986) 
enfoque meramente lógico-deductivo de sus decisiones como lo hacía el formalismo. La clave parece ser que el derecho es una práctica social y por tanto tiene importancia para que los usuarios, la comunidad académica o la comunidad de jueces consideren sobre las razones expuestas en un ámbito de deliberación judicial. El juez debe escoger normas y ofrecer un significado a sus decisiones, o en el caso de no encontrar una ley aplicable, ofrecer un razonamiento moral. Dicho de una manera sencilla, el paso del silogismo a la argumentación permite que la interpretación ofrezca cierta seguridad institucional.

La disyuntiva volitiva/cognitiva, sin embargo, no parece disolverse. Por el contrario, la argumentación no abandona la voluntad del juez, interpretar es un acto discrecional, aunque sin duda no del todo irracional. Ese es el punto sostenido en este documento. En efecto, las decisiones motivadas de los jueces tienen un impacto social y están sujetas a la crítica pública o a las comunidades de expertos. El juez debe esforzarse por construir argumentos sólidos y coherentes. Empero, tampoco podemos decir que desaparezca su postura ideológica, su cálculo político o su influencia cultural. Las decisiones son interpretaciones y dotan de sentido las reglas, los principios o las normas que pueden inclinarse a diferentes lados de la balanza, incluso, ser fracturados con aparente coherencia.

Lo claro es que los jueces en el ordenamiento colombiano están preocupados por ofrecer motivaciones coherentes a sus decisiones y mantener un "decoro" cognitivo que es determinante para sostener la legitimidad social que goza la Corte Constitucional colombiana. No se puede perder el punto de vista, que la voluntad de los jueces no existe por fuera de un sistema social, de unas circunstancias políticas, de una opinión pública que de alguna manera constriñe las decisiones pero que sin duda es siempre difícil medir. Las interpretaciones judiciales forman parte de un contexto delimitado por las condiciones sociales, económicas y políticas del espacio-tiempo donde se producen. La voluntad y el conocimiento de la práctica judicial están influenciadas por el campo jurídico y a su vez, en mayor o menor medida, por los otros campos que dan forma a la sociedad.

La tarea que resta desde el análisis académico, es desentrañar ambas 
dimensiones, la volitiva y la cognitiva, dentro de una mirada comprensiva de sus decisiones. Entender e interpretar las sentencias de la Corte Constitucional significa estudiar los argumentos jurídicos desde su propia racionalidad jurídica pero no exclusivamente. El establecimiento de los problemas jurídicos, las reglas de aplicación, las motivaciones y las decisiones de los jueces deben contrastarse con elementos "externos" o contextuales que permitan entender o, al menos, hipotéticamente plantear, las influencias y posiciones no-jurídicas de sus decisiones, tal como lo plantea Duncan Kennedy.

\subsection{Matriz de Posiciones y Línea Jurisprudencial}

Un grupo de sentencias sobre una misma temática son posiciones articuladas a un conjunto de leyes, motivaciones y decisiones judiciales que se relacionan, distancian y difieren sobre un asunto similar; son un movimiento de posturas que discuten la realidad social a través de casos particulares, que tienen mayor o menor relevancia dentro de la agenda de un país, según el tiempo y el espacio que son producidas y/o estudiadas. Las decisiones judiciales operan como discursos que ordenan la realidad, limitan o permiten la vida de las personas en diferentes ámbitos. En el caso de los derechos fundamentales ponen en juego muchas veces aspectos sensibles como la propia supervivencia o la vida futura de humanos en particulares contextos. Para lograr establecer este "cuadro de movimientos" es necesaria usar una herramienta de racionalización del derecho conocida como línea jurisprudencial.

La línea jurisprudencial es una herramienta para observar el proceso histórico de producción de decisiones por medio de una pregunta o problema jurídico para identificar en un espacio abierto de posibles respuestas. Diego López afirma que la pregunta planteada para la elaboración de una línea jurisprudencial "es una estrategia conveniente para graficar las soluciones que la jurisprudencia ha dado al problema y para reconocer, si existe un patrón de desarrollo decisional" ${ }^{12}$. En el presente artículo la

12 LÓPEZ, (2000), p. 56. 
pregunta jurídica es: ¿Se garantiza plenamente el derecho fundamental a la salud, la integridad y la vida digna a los extranjeros en situación migratoria irregular en Colombia por la Corte Constitucional?

Como el objetivo de identificar los cambios posicionales, la respuesta hipotética al problema jurídico planteado tiene dos extremos: a. No garantiza a los migrantes por su condición de irregularidad y b. Garantiza sin importar la condición irregular del migrante. Como se observa en el cuadro, es posible reconocer las posiciones de cada una de las sentencias y los patrones de cambio. Para establecerlas no basta con reconocer la decisión, es necesario ubicar las principales posturas y argumentos jurídicos esgrimidos y tener en cuenta la cercanía entre los motivadores fácticos de cada acción de tutela presentada. Nótese que los hechos que motivan el litigio son importantes porque determinan el problema jurídico planteado por el juez y sus consecuentes consideraciones para abordarlo.

El gráfico 1. es el resultado del estudio de las sentencias. Se puede observar fácilmente las posiciones que se dirigen hacia una u otra solución durante el periodo 2016 a 2019. Se encuentran dos tipos de sentencias principales: sentencias hito y sentencias confirmadoras de principios ${ }^{13}$. Las sentencias hito definen una subregla de derecho, originan cambios en la línea, tienen un peso importante porque estructuran una visión del problema jurídico e influencian decisiones siguientes. Por el contrario, las sentencias confirmadoras de principios, tienen obediencia a la sentencia anterior, se acogen a reglas anteriores para decidir su caso y usualmente son la gran mayoría. Las sentencias hito están marcadas con el símbolo [D] y las sentencias confirmatorias así D.

Las sentencias hito [D] son las T-314/2016 y la SU 677/2017 que se encuentran en posiciones opuestas a la pregunta motivadora. Vale la pena aclarar que su lugar obedece más a los hechos que motivaron la acción de amparo constitucional que a los argumentos jurídicos ofrecidos como será explicado más adelante. Las demás sentencias reproducen argumentos, agregan ligeros matices, organizan sus razones adecuándolas a

13 LÓPEZ, (2000) 
los hechos presuntamente vulneradores de los derechos fundamentales. A continuación, serán presentadas las posiciones, argumentos y debates promovidos por el objetivo del artículo.

No garantiza por su condición de irregularidad

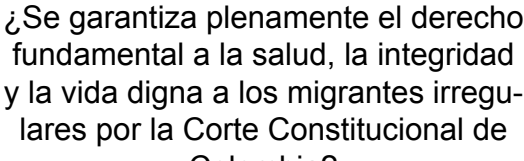
lares por la Corte Constitucional de Colombia?

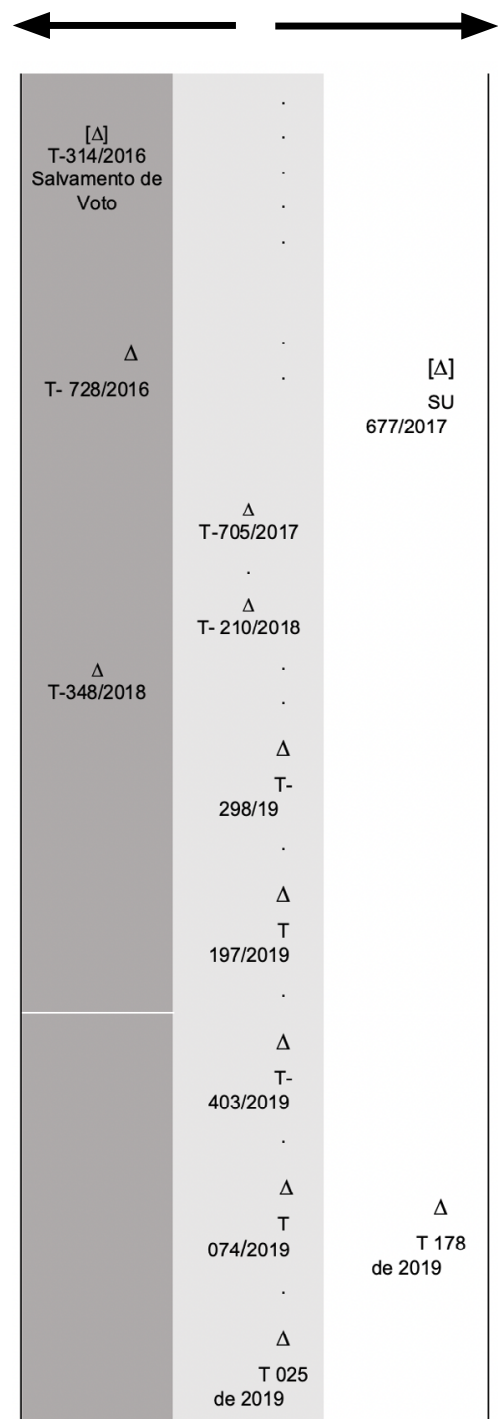

Garantiza sin importar la condición irregular del migrante

Figura 1. Línea Jurisprudencial. Matriz de posiciones (elaboración propia, 2020) 


\section{Las posiciones de la Corte Constitucional: entre la nuda vida y el amparo constitucional}

Los estudios contemporáneos sobre migración y refugio cuestionan cada vez más los alcances y consecuencias negativas de la política y el derecho sobre las vidas humanas en situación de inminente movilidad transfronteriza ${ }^{14}$. En su versión clásica, los estudios de Walter Benjamín, Hannah Arendt o Giorgio Agamben han sido destacados al considerar las implicaciones del derecho, el poder y la vida sobre poblaciones o grupos excluidos. En particular, el modelo biopolítico de poder expuesto por Giorgio Agamben coincide con la vida de los apátridas, los desterrados y refugiados. Usando la categoría de nuda vida, Agamben señala que todos los humanos son biológicos pero, no todos cuentan con una vida cualificada que les permita vivir como seres políticos dentro de una comunidad o grupo. Señala que algunas vidas son reducidas a su expresión biológica cuando son expulsadas de su contenido político por medio de una regla de excepción establecida por la estructura jurídico-política del Estado.

La excepcionalidad para Giorgio Agamben se conecta con la noción de Homo Sacer, "una oscura figura del derecho romano arcaico, en que la vida humana se incluye en el orden jurídico bajo la forma de exclusión (es decir, la posibilidad absoluta de que cualquiera le mate)"15. Significa que una persona desterrada de su comunidad política se le reduce a la simple existencia biológica (nuda vida) y queda expuesta a la muerte por medio de la desprotección del cuerpo jurídico-político. Es el caso de ciertos grupos que son excluidos de la protección legal porque el derecho incluye esa posibilidad y normaliza la excepción:

"no queda sencillamente fuera de la ley, ni es indiferente a ésta, sino que es abandonado por ella, es decir, que queda expuesto y en peligro en el umbral en que vida y derecho, exterior e interior se confunden. De él no puede decirse literalmente si está fuera o dentro del orden jurídico"

14 AAS, (2011).

15 Agamben (1997). p. 17. 
${ }^{16}$ (cursiva en texto).

La regla de excepción acepta la universalidad e igualdad de los derechos, pero incluye una insólita posibilidad en la que encajan migrantes y refugiados. La regla de excepción tiene la característica de dividir personas, confiriendo 'privilegios' y suspendiendo 'excepcionalmente' derechos que exponen de forma dramática a seres humanos en condiciones de vulnerabilidad a la muerte. La excepción en el ordenamiento jurídico-político colombiano quedó establecida en la Constitución Política de 1991 y desarrollada en los recientes actos administrativos del gobierno nacional para conjurar la masiva llegada de ciudadanos venezolanos.

En el ordenamiento constitucional ${ }^{17}$ la regla de excepción existe como línea que divide a los nacionales y extranjeros. Aunque la Constitución Política reitera la universalidad e igualdad de los derechos al afirmar que "los extranjeros disfrutarán en Colombia de los mismos derechos civiles que se conceden a los colombianos" inserta la figura jurídica de excepción al señalar: "No obstante, la ley podrá, por razones de orden público, subordinar a condiciones especiales o negar el ejercicio de determinados derechos civiles a los extranjeros" ${ }^{18}$. Y más adelante reitera: "Así mismo, los extranjeros gozarán, en el territorio de la República, de las garantías concedidas a los nacionales, salvo las limitaciones que establezcan la Constitución o la ley"19.

La suspensión de derechos quedó actualizada por medio de los decretos que en clave binaria dividieron a los migrantes en regulares e irregulares, inclusión/exclusión. La regularidad según los actos administrativos del gobierno es el status jurídico del migrante que cumple los requisitos fijados por el Estado para permanecer 'legalmente' mientras la migración

16 Agamben, (1997) p. 44.

17 A partir del año 1991, Colombia consensuó un nueva Constitución Política de corte garantista, refundó el pacto social con el nuevo Estado Social de Derecho, puso acento en la defensa de los derechos humanos fundamentales y la igualdad de las personas ante la ley sin "oportunidades sin ninguna discriminación por razones de sexo, raza, origen nacional o familiar, lengua, religión, opinión política o filosófica" Constitución Política de Colombia de 1991.

18 Constitución Política de Colombia de 1991, art. 100.

19 Constitución Política de Colombia de 1991, art. 100. 
irregular se profesa de las "personas que se desplazan al margen de las normas de los Estados de salida, tránsito o receptor [...] el migrante no tiene la autorización necesaria, ni los documentos requeridos por las autoridades de inmigración para ingresar, residir o trabajar en un determinado país"20.

La Corte Constitucional se vio avocada a tomar posición frente a la suspensión de derechos proveniente de la regla de excepción constitucional y administrativa que naturaliza la exclusión de los migrantes en situación de irregularidad. Las decisiones del alto tribunal constitucional tuvieron diferentes alcances a la hora de interpretar el derecho a la salud y la vida digna. Una posición asumió con rigor la regla de excepción y suspendió radicalmente la atención médica integral. Otra posición reiteró la regla de excepción, pero concilió entre la absoluta desprotección y la protección constitucional, ampliando el concepto de 'urgencias' a ciertas enfermedades consideradas catastróficas. Una tercera, sin negar la excepcionalidad, buscó ser garantista y ofreció protección constitucional usando la noción de 'urgencias' como sinónimo de atención integral, particularmente en los casos de embarazo, parto y cuidados médicos posteriores para la madre como al bebé. En su conjunto, ninguna fue radicalmente garantista, ni obligó al Estado a buscar mecanismos administrativos contundentes que condujeran a la real protección de los derechos a la salud, la vida y la integridad de accionantes venezolanos con status migratorio irregular, como será visto a continuación.

\subsection{La regla de Excepción y la Nuda Vida}

En el año 2016 la Corte Constitucional se pronunció sobre dos casos de migrantes en situación irregular que invocaron la protección de los derechos a la salud y la vida digna: las sentencias T-314 de 2016 y la T-728 de 2016. Ninguna trata sobre migrantes venezolanos, sin embargo, la primera se convirtió en un referente importante para decisiones posteriores.

La sentencia T-314/2016 revisó el caso de un ciudadano argentino que

20 Organización Internacional de las Migraciones, (2006) p. 34. 
padecía diabetes y había sido hospitalizado e intervenido quirúrgicamente producto de su enfermedad. Sus condiciones económicas eran precarias para sufragar gastos médicos. Solicitó amparo constitucional porque, aunque le realizaron atención de urgencias le negaron medicamentos y tratamientos necesarios para su recuperación y tratar su enfermedad. La razón fue su condición migratoria irregular y, por tanto, no se le vinculó al Sistema General de Seguridad Social en Salud (SGSSS) del Estado que sería el procedimiento administrativo idóneo para preservar sus derechos fundamentales ${ }^{21}$.

La Corte Constitucional a pesar de mostrarse de acuerdo con la obligación del Estado de ofrecer el servicio público de Seguridad Social en Salud para todas las personas determinó que no le fue vulnerado el derecho fundamental a la salud al no conceder los medicamentos y tratamientos necesarios. Argumentó que la afiliación a salud no fue posible porque el accionante no portaba un documento válido por su condición de migrante irregular y fue enfática al afirmar que el extranjero estaba vulnerando la ley migratoria del país. Reconoció que el 'migrante irregular' obtuvo el derecho a salud porque recibió 'atención de urgencia' para atender sus necesidades elementales y primarias, pero continuar con procedimientos médicos no era obligación del Estado colombiano. Con esta aseveración, la responsabilidad sobre su vida pasó de las instituciones al accionante, quien tendría que buscar la manera de regularizar su situación migratoria para recibir la atención completa en salud. Así pues, se fundaron las principales reglas jurisprudenciales posteriormente aplicadas a casos de migrantes venezolanos en situación irregular:

"(i) deben ser tratados en condiciones de igualdad respecto de los nacionales colombianos; (ii) tienen la obligación de cumplir la Constitución Política y las leyes establecidas para todos los residentes en Colombia; (iii) tienen derecho a recibir un mínimo de atención por parte del Estado en casos de urgencia con el fin de atender sus necesidades básicas, especialmente las relacionadas con asuntos de salud" 22 (cursivas fuera de 
texto)

La regla ii, acoge la regla de excepción, al plantear la igualdad de derechos civiles y políticos a colombianos y extranjeros, pero resalta que la igualdad no es absoluta. Los derechos pueden ser subordinados a condiciones especiales e incluso negados por razones de orden público, como fue explicado arriba. Más tarde, la Sentencia 348 de 2018 decidió en la misma lógica el caso de un ciudadano venezolano no regularizado, diagnosticado con Virus de la Inmunodeficiencia Humana VIH, al que se le negaron los medicamentos "emtricitabina o tenofovir" y "efavirenx", prescritos por el médico. Se determinó que el derecho a la salud de los migrantes en situación irregular se traduce exclusivamente a la atención básica de urgencia y decide negar el amparo constitucional porque "no se puede concluir que la entrega de antirretrovirales se encuentre dentro del concepto de urgencia"23.

Las tres sentencias resultan extrañas si recordamos que la CCC es el más alto tribunal creado en 1991 para guardar la integridad y supremacía de la Carta Política y los derechos fundamentales de las personas sin importar su orientación o condición ideológica, nacional, racial, sexual o religiosa cuando son "vulnerados o amenazados por la acción u omisión de cualquier autoridad pública o de los particulares en los casos que señale la ley"24. Así lo entiende el Salvamento de Voto del magistrado Jorge Iván Palacio Palacio a la T 314/16 al sostener que los argumentos excluyen de su consideración el derecho a la dignidad humana del actor, y el carácter universal del derecho a la salud 25.

Su postura enfatiza que el status de irregularidad migratoria no puede despojar su calidad de persona y que sus derechos le son implícitos porque es un ser humano y no por su nacionalidad o legalidad. El magistrado alegó que el impedimento administrativo de afiliación al sistema de salud niega el carácter de universalidad del servicio. Recordó que la

23 Corte Constitucional, Sentencia T-348 de 2018, de 28 de agosto de 2018.

24 Corte Constitucional de Colombia, sentencia T-348 de 2018, de 28 de agosto de 2018.

25 Salvamento de Voto Gloria Stella ORTIZ, Corte Constitucional de Colombia, sentencia a T-348 de 2018, de 28 de agosto de 2018. 
Sentencia T-760 de 2008 dejó en claro que nadie puede ser excluido del acceso a los servicios de salud y que es obligación del Estado "garantizar 'a todas las personas el acceso a los servicios de promoción, protección y recuperación de la salud', 'conforme a los principios de eficiencia, universalidad y solidaridad'” 26.

\subsection{El derecho a la salud como 'urgencia'}

\subsubsection{Enfermedad Catastrófica}

La segunda posición de la CCC aplica la regla de excepción con visos más garantistas. Las sentencias de este rango retoman las tesis de la Sentencia T-314/16 pero expanden el concepto de urgencias, incluyendo enfermedades catastróficas, protección a los derechos sexuales y reproductivos de las mujeres y a los recién nacidos. La noción de 'atención de urgencias' es una garantía mínima del derecho a la salud "con el fin de preservar la vida cuando no haya un medio alternativo, [y] la persona no cuente con recursos para costearlo y se trate de un caso grave y excepcional" 27

La noción de 'urgencias' se convirtió en clave para otorgar amparo constitucional sin entrar en contradicciones con la regla de excepcionalidad. Así lo demuestra la Sentencia T-210 de 2018 al tratar dos casos diferentes, una mujer con avanzado estado de cáncer de útero y, un niño que padecía hernias inguinal y umbilical. Ambos, personas venezolanas, recibieron atención de urgencias pero les fue negada la atención médica para tratar sus enfermedades en razón de su condición migratoria irregu$\operatorname{lar}^{28}$. La Corte decidió, en el caso de la mujer, otorgar la protección constitucional ya que la urgencia debería incluir los tratamientos de radioterapia y quimioterapia que fueran establecidos por un médico tratante como procedimientos inminentes para reducir el riesgo de muerte de la paciente. Sobre la hernia del niño sigue el mismo razonamiento al afirmar que

26 Citado en Salvamento de Voto, Gloria Stella OrTIz, Corte Constitucional de Colombia, sentencia T-348 de 2018, de 28 de agosto de 2018.

27 Corte Constitucional de Colombia, sentencia T-705 de 2017, de 30 de noviembre de 2017.

28 Corte Constitucional de Colombia, sentencia T-210 de 2018, de 1 de juno de 2018. 
el médico consideró que podría ponerse en riesgo la vida del menor sin la cirugía de reparación. En ambos casos, los procedimientos solicitados amplían la categoría de lo 'urgente' y mitigan el argumento del status de irregularidad como impedimiento para tratamientos más profundos que la simple "estabilización de salud del paciente" ${ }^{29}$.

La inclusión de enfermedades catastróficas a la categoría de urgencia es reconocida también en las sentencias T-197 de 2019 y la T-403 de 2019. La primera sigue la línea argumentativa de 'urgencia ampliada' e inserta la enfermedad de carcinoma de células escamosas moderadamente diferenciado. La decisión de la sentencia T-403/19 es similar. La ciudadana venezolana es diagnosticada en Venezuela con carcinoma ductal infiltrante en la mama izquierda. La Corte afirma que los extranjeros tienen derecho a recibir una atención de urgencias que en esta circunstancia "comprende la remisión a la entidad del nivel de complejidad requerido" ${ }^{30}$ como lo reitera la ley y la jurisprudencia.

La inclusión de enfermedad catastrófica como urgencia evoluciona en la Sentencia T-025 de 2019 al incluir el tratamiento al VIH de migrante en situación irregular que en caso similar había sido negada anteriormente en la Sentencia T-348/18. La decisión asumió que la Secretaría de Salud de Cartagena había vulnerado los derechos fundamentales al no entregar los medicamentos señalados por el médico tratante y exponer su vida al peligro de muerte ${ }^{31}$.

\subsection{Embarazo, parto y afiliación de menores}

Otra variación en la categoría 'urgencias' fue la inclusión de los estados de embarazo, cuidados prenatales, atención posteriores al parto y protección a los recién nacidos considerados en la sentencia SU 677 de 2017 y las sentencias T-074, T-298 y T 178 de 2019. La Sentencia Unificada 677 de 2017 marcó un hito al dejar en claro que los cuidados prenatales, la asistencia al parto y los cuidados posteriores de la madre como del

29 Corte Constitucional de Colombia, sentencia T-705 de 2017, de 30 de noviembre de 2017.

30 Corte Constitucional de Colombia, sentencia T-403 de 2019, de 30 de agosto de 2019.

31 Corte Constitucional de Colombia, sentencia T-025 de 2019 de 29 de enero de 2019. 
bebé son una ampliación del concepto de 'urgencias'. La Corte consideró que las mujeres en situación irregular tienen derecho a la atención básica de los servicios de salud materna que, en términos puntuales, debe ser integrales más que la simple estabilización médica en situación extrema de enfermedad. El argumento de la sentencia es que "la negativa a la prestación de estos servicios como una urgencia, en muchos casos lleva a la muerte de la madre, del feto y del recién nacido"32. Reconoció que el proceso de migración masiva irregular contribuye a generar un alto riesgo en la salud de las mujeres embarazadas; argumentó que en otras sentencias es nombrado pero pocas veces había contribuido a ampliar los servicios de atención médica como traducción del derecho a la salud.

La Corte tuvo que considerar un nuevo hecho en este caso. El 21 de agosto de 2016 la mujer dio a luz a una niña y se vio en la obligación de juzgar la posible vulneración de los derechos a la recien nacida. Observó que el Prestador de Salud está obligado a afiliar al SGSSS al recién nacido cuando sus padres no lo estén o no cumplan con los requisitos para acceder al mismo. Recordó que la bebé es un sujeto de especial protección constitucional y merece un trato preferente.

En el mismo sentido e inspirado por la SU-677/17, la sentencia T-178 de 2019, dio amparo constitucional a un niño de padres venezolanos, con permanencia irregular, nacido en territorio colombiano al que se le negó la afiliación al SGSSS con el argumento de que los padres del menor no contaban con nacionalidad colombiana. Reitera la Corte que

"en el caso del acceso a servicios de salud de los niños y niñas recién nacidos de padres extranjeros en situación irregular, le corresponde al prestador de servicios de salud registrar al recién nacido en el Sistema de Afiliación Transaccional e inscribirlo en una EPS del régimen subsidiado en el respectivo municipio" 33 .

La Sentencia 298/19 se pronuncia sobre los hechos de una mujer venezolana en condición de irregularidad un estado de embarazo de alto

32 Corte Constitucional de Colombia, sentencia unificada SU 677 de 2017, de 15 noviembre de 2017.

33 Corte Constitucional de Colombia, sentencia T-178 de 2019, de 6 de mayo de 2019. 
riesgo a la que le fueron negados los controles prenatales por su status migratorio. La Sentencia reconoce que aunque el embarazo no es considerado una urgencia, el particular lo era por el riesgo a la vida de la mujer, del feto y del recién nacido. Quizás lo más revelador de la decisión es afirmar que "la atención médica de las mujeres gestantes (servicios médicos prenatales, de parto y posnatales), obedece al ejercicio de los derechos sexuales y reproductivos de las mujeres que requieren ser prestados de forma urgente por las instituciones prestadoras de salud" 34 (negrillas fuera de texto) en armonía con la sentencia hito. Así mismo, la T-074 de 2019 considera que se vulneraron los derechos fundamentales y la seguridad social de una mujer venezolana en estado de embarazo bajo los argumentos de su condición irregular y ausencia de requisitos de afiliación al sistema de salud.

Sin duda, la SU-677/17 aportó una mirada más integral al considerar que la prestación de los servicios de salud relacionados con el embarazo y el parto deben considerarse de forma urgente, y reconoce que su desatención puede llevar a la muerte, particularmente "en situaciones de crisis humanitaria como la que actualmente ocurre en el Estado colombiano por la migración masiva de ciudadanos venezolanos" ${ }^{35}$. Sin embargo, la aclaración de voto y el salvamento parcial de voto a la SU-677/17 pone de manifiesto las discusiones al interior de la Corte sobre el fenómeno migratorio venezolano.

La aclaración de voto se muestra reacia al aceptar la decisión de proteger constitucionalmente a las mujeres embarazadas en situación de irregularidad sin que la 'urgencia' fuera determinada por un médico. Alega la importancia de establecer un filtro que precise el alcance de los servicios médicos de los migrantes en situación irregular: "el concepto del profesional de la salud [es] el que permite establecer, con base en un criterio científico, cuando se requiere un servicio con necesidad"3610/05/20

34 Corte Constitucional de Colombia, sentencia T-298 de 2019, de 28 de junio de 2019.

35 Corte Constitucional de Colombia, sentencia unificada 677 de 2017, de 15 noviembre de 2017.

36 Aclaración de Voto, Corte Constitucional de Colombia, sentencia a T-348 de 2018, de 28 de agosto de 2018. 
8:24:00 a. m.. Al parecer, recomienda que la condición de embarazo y toda la atención básica de salud no constituye un derecho a la urgencia y, por tanto, no puede ser predicada para todos los extranjeros, solamente aquellos en una 'verdadera urgencia'.

Por su parte, el salvamento parcial de voto reclama que la mayoría de la sala ignoró la perspectiva de género. Consideran que 'olvidar' el género significa reproducir ideas dominantes y perder la oportunidad de reducir o eliminar prácticas de desigualdad. Por tanto, aunque no se invocara, debería ser iniciativa del juez establecer la perspectiva de género en el supuesto de situaciones asimétricas de poder formados por estructuras patriarcales o en contextos donde se revelan dichas inequidades basadas en el sexo, los roles estereotipados o las orientaciones sexuales. Los firmantes reproducen el borrador que había sido presentado a la Sala para demostrar de qué manera la decisión final había desnaturalizada el enfoque de género, pese a que finalmente, ofrece el amparo constitucional a la mujer embarazada y a la recién nacida, a esta última si le aplica un enfoque diferencial (sujeto especial de protección).

La protección constitucional del conjunto de sentencias estudiadas en este apartado, progresivamente fue incorporando nuevos elementos fácticos a la idea de "urgencia" que, como se vio, contienen debates internos y sostienen la excepcionalidad a extranjeros como un punto arquidémico de sus decisiones. Por tanto, podemos señalar que sin despercudirse de la regla de excepción, algunas sentencias, buscaron traducir el derecho a la salud a la atención médica integral y no solo a la urgente y limitada. Sin embargo, vale la pena hacer consideraciones finales que pongan en discusión los argumentos de la Corte y ofrezcan tentativas razones a las decisiones tomadas y que no parecen residir claramente en el texto judicial.

\section{Conclusiones}

Una valoración crítica de las posturas de la Corte Constitucional conduce a cuestionar su timidez para otorgar el amparo constitucional a las personas vulnerables argumentando su condición migratoria. Primero, 
es preocupante la aseveración de la Corte Constitucional que afirma que la regularización es la única opción para hacer efectivo el derecho a la salud visto como atención médica integral. Los magistrados conocen perfectamente las condiciones materiales y jurídicas que hacen imposible que miles de venezolanos puedan cumplir con los requisitos exigidos para optar por un Permiso Especial de Permanencia o una Visa de Residente $^{37}$. Las trabas administrativas son mayúsculas si tenemos en cuenta que a lo largo de las convocatorias a optar por un PEP cientos de miles de venezolanos no han contado con pasaporte vigente o acceso por Punto de Control Migratorio. Las dificultades económicas y administrativas para acceder a un pasaporte en el país de origen, mantener a salvo sus documentos personales o el paso a Colombia por los miles de kilómetros de frontera de trochas y ríos, son reconocidos -por la misma jurisprudencia- como una crisis humanitaria proveniente de la migración masiva. Desafortunadamente, las decisiones judiciales estudiadas, en buena manera refuerzan las barreras administrativas a las que se ven expuestos los extranjeros con permanencia irregular. Las decisiones a la luz del derecho internacional reconocido por Colombia, las leyes nacionales y la misma jurisprudencia Constitucional contienen argumentos débiles, que terminan dejando de lado el discurso garantista de la salud y la vida para centrarse en las obligaciones de regularización de los extranjeros, o lo que es lo mismo, la exposición a la nuda vida de miles de personas en condición de alta vulnerabilidad.

Segundo, la aplicación de la regla de excepción parece tener una razón que supera la jurídica: la económica, particularmente, la fiscal. Sin llegar a desarrollarlo con claridad, la jurisprudencia invoca los límites del servicio de salud a la disponibilidad presupuestal: "la complejidad de este derecho, no sólo redunda en las acciones y omisiones por parte del Estado y la sociedad, sino también implica que se cuente con suficientes

37 Así lo reconoce la Resolución 2/18 de la CIDH "Ante la falta de canales legales, regulares y seguros para migrar, muchas personas no han tenido otra opción que recurrir a canales clandestinos que provee la migración irregular, a través de riesgosas rutas terrestres y marítimas". 
recursos materiales e institucionales que permitan su goce efectivo"38 (negrillas fuera de texto). Es indudable que los derechos fundamentales para ser garantizados necesitan presupuesto y eficacia en la ejecución, sin embargo, como reseña Vargas del Campo

"la Alta Corporación, ha señalado que el problema central no puede ser la existencia de dificultades de tipo económico... es claro y determinante lo señalado en el artículo 366 de la Constitución Política... el bienestar general y el mejoramiento de la calidad de vida son finalidades sociales del Estado y su objetivo fundamental será la solución de las necesidades insatisfechas en salud" 39

En las palabras sencillas, el rubro destinado por el Estado a cumplir el derecho a la salud debe ser prioritario y, con mayor razón, la Corte Constitucional no pude esgrimir como argumento la del estadista. Su labor no es discutir la distribución política de los recursos de la nación o su disponibilidad financiera sino proteger los derechos prioritarios de las personas. Mantener latente el argumento económico significaría un retroceso imperdonable de la jurisprudencia constitucional. Usar la excusa de la "irregularidad migratoria" sienta un precedente negativo que impacta todas las regiones del país donde cientos de jueces de tutelas asumen las posturas del alto tribunal.

Tercero, según el propio ordenamiento interno, el Estado debe proteger y garantizar el goce efectivo del derecho fundamental a la salud. La Corte Constitucional tiene los elementos de validez normativa para que se aplique a norma superior en consonancia con las leyes específicas que protegen el derecho fundamental de la salud. Particularmente, es obligación garantizar el servicio integral de salud aplicando los principios de universalidad, aplicar las normas vigentes más favorables y adoptar y promover las políticas públicas dirigidas a los grupos más vulnerables, que en este caso y como los reconoce el derecho internacional son los migrantes en situación migratoria irregular.

Finalmente, cuando los organismos internacionales instan a los Esta-

38 Corte Constitucional de Colombia, sentencia T-348 de 2018, de 28 de agosto de 2018.

39 Vargas del Campo (2017), p. 90. 
dos a revisar y formular sus políticas migratorias para enfrentar la discriminación, eliminar las barreras de acceso a servicios básicos y capacitar a todos los funcionarios para evitar barreras administrativas, lo hacen preocupados por los evidentes hechos de vulneración a sus derechos fundamentales. Por tanto, decisiones judiciales basadas en razones jurídicas o económicas discriminatorias profundizan la desprotección de la vida y la exponen con rigurosidad a la muerte. Lamentablemente, fomentan un orden en el que existen "vidas descartables" que son despojadas de su carácter jurídico. Es necesario, que la interpretación de los jueces no se entrelace por razones culturales, económicas o políticas a la trágica producción moderna de "vidas desperdiciadas".

\section{Bibliografía}

AAs, Katja, (2011) “'Crimmigrant' bodies and bona fide travelers: Surveillance, citizenship and global governance , Theoretical Criminology, (Vol. 15, $n^{\circ} 3$ ) pp. 331-346.

Agamben, Giorgio, (1997): Homo sacer. El poder soberano y la nuda vida, (Valencia: Pre-textos).

Bourdieu, Pierre (1987): "The force of law: Toward sociology of the juridical field”, Hastings Law Journal, (Vol. 38, n 5), pp. 814-854.

GREEN, Michael Steven (2005): "Legal Realism as Theory of Law", William and Mary Law Review, (Vol. 46, $\mathrm{n}^{\circ}$ 6), pp. 1915-2000.

HutCheson, Joseph C.Jr., (1929): "Judgment Intuitive The Function of the Hunch in Judicial Decision”, Cornell Law Quarterly, (Vol. 14, n³), pp. 274-288.

LóPez MedinA, Diego Eduardo (2000): El derecho de los jueces: obligatoriedad del precedente constitucional, análisis de sentencias y líneas jurisprudenciales y teoría del derecho judicial, (Bogotá: Editorial Legis). MacCormick, N. y Weinberger, Ota, (1986): An Institutional Theory of Law: New Approaches to Legal Positivism, (Dordrecht: Springer Science \& Business Media)

Migración colombia, (2019) Radiografía Venezuela. Corte a 31 de Octubre de 2019. Bogotá. 
Thomas, E.W., (2005): The Judicial Process: Realism, Pragmatism, Practical Reasoning and Principles (Cambridge: Cambridge University Press)

VARGAS DEL CAMPO, José Rodrigo, (2017): "¿Se desjudicializa la salud con la aplicación de la Ley Estatutaria en Salud?", en AAVV. Derecho fundamental a la salud: ¿nuevos escenarios? (Bogotá, Universidad Nacional de Colombia) pp. 89-92.

\section{Jurisprudencia Citada ${ }^{40}$}

Miguel Ángel Villela Meza con Cafesalud EPS (2016) Corte Constitucional de Colombia 16 de diciembre 2016 (Acción de Tutela) sentencia T-728 de 2016. Magistrado Ponente. Alejandro Linares Cantillo.

Carlos Walter Schule con Secretaría de Planeación Distrital y el Fondo Financiero Distrital de Salud de Bogotá D.C (2016). Corte Constitucional de Colombia 17 de junio de 2016 (Acción de Tutela) sentencia T- 314 de 2016. M.P. Gloria Stella, Ortiz Delgado.

Tiresias en calidad de agente oficioso de Lucina con el Hospital Estigia (2017) Corte Constitucional de Colombia 15 noviembre de 2017 (Acción de Tutela) sentencia SU 677 de 2017, Magistrada Sustanciadora Gloria Stella, Ortiz Delgado.

CEOS con el Instituto de Salud de Norte de Santander (2017) Corte Constitucional de Colombia 30 de noviembre de 2017 (Acción de Tutela) sentencia T-705 de 2017. Magistrado Ponente.. José Fernando, Reyes

Yeraldín con el Instituto de Salud de Norte de Santander (2018) Corte Constitucional de Colombia 1 de juno de 2018 (Acción de Tutela) sentencia T-210 de 2018. Magistrado Ponente. Gloria Stella Ortiz

David con Instituto de Salud de Norte de Santander (2018), Corte Constitucional de Colombia 28 de agosto de 2018 (Acción de Tutela) sentencia T-348 de 2018. Magistrado Ponente. Luis Guillermo Guerrero.

40 La jurisprudencia citada es publicada en la página web de la Corte Constitucional de Colombia y ha sido tomada de allí en su versión digital. Toda la jurisprudencia accesible en: http://www. corteconstitucional.gov.co. 
María con Secretaría de Salud de Barranquilla (2019) Corte Constitucional de Colombia 30 de agosto de 2019 (Acción de Tutela) sentencia T-403 de 2019. Magistrado Ponente. Luis Guillermo Guerrero.

Delgado con Secretaría de Salud de Buga (2019) Corte Constitucional de Colombia 14 d mayo de 2019 (Acción de Tutela) sentencia T-197 de 2019. Magistrado Ponente. Diana, Fajardo Rivera.

Dayari con Secretaría de Salud de Risaralda (2019) Corte Constitucional de Colombia 25 de febrero de 2019 (Acción de Tutela) sentencia T-074 de 2019, Magistrado Ponente. Antonio José, Lizarazo Ocampo JJHM con DNP (2019) Corte Constitucional de Colombia 6 de mayo de 2019 (Acción de Tutela) sentencia T-178 de 2019, Magistrado Ponente. Cristina, Pardo Schlesinger.

Taborda con El Hospital Remedios Rioacha (2019) Corte Constitucional de Colombia 28 d ejunio de 2019 (Acción de Tutela) sentencia T-298 de 2019. Magistrado Ponente. Alberto Rojas Ríos.

Rodrigo con Secretaria de Salud Santa Marta (2019) Corte Constitucional de Colombia 29 de enero de 2019 (Acción de Tutela) sentencia T-025 de 2019. Magistrado Ponente. Alberto Rojas Ríos.

\section{Normas jurídicas citadas}

Constitución Política de Colombia de 1991. Gaceta Constitucional (Colombia), 20 de julio de 1991.

Ley Estatutaria 1751 de 2015. Por medio de la cual se regula el derecho fundamental a la salud y se dictan otras disposiciones. Diario Oficial No. 49.427 (Colombia), 16 de febrero de 2015

\section{Resoluciones de la Corte IDH}

CORTE IDH, Resolución 2 de marzo de 2018. 